\title{
A
}

Acta HealthMedica

Volume: 2, Issue: 1, January-March 2017, Pages: 148, DOI: http://dx.doi.org/10.19082/ah148

\section{DEVELOPMENT OF AN ASSESSMENT METHOD FOR CHRONIC DISEASE MOBILE HEALTH APPLICATIONS}

\author{
Kiana Farhadyar ${ }^{1}$, Farhad Fatehi ${ }^{2}$
}

1: School of Allied Medical Sciences, Tehran University of Medical Sciences, Tehran, Iran.

2: Centre for Online Health, University of Queensland, Brisbane, Australia; Australian eHealth Research Centre, CSIRO, Brisbane, Australia.

Correspondence:

Kiana Farhadyar, Student in Master Degree, Tel: +989127795827, E-mail: K.farhadyar@gmail.com

\section{TYPE OF ARTICLE: CONFERENCE ABSTRACT}

\begin{abstract}
Introduction: According to the substantial growth of mobile health applications in all aspects of health in the last decade, an mHealth app assessment has become more important for developers. On the other hand, the increasing rate of chronic diseases in all communities has encouraged the developers to develop applications for chronically ill patients. The aim of this study was to develop an assessment method for mobile health apps to fit specifically to chronic diseases mobile health apps.

Methods: The methodology of this research had three steps. In the first step, the authors searched the literature for the assessment tools for chronic disease mobile applications. In the next step, the best tool for matching an application to the users' needs, which was also adaptable to Rinke Riezebos's scoring method, was selected. Then, in the last step of this methodology, a tool was first prepared and then adapted to the Riezebos's scoring method in order to attach it to this scoring method as a relevant subsection.

Results: Step one showed limited tools have been designed specific to chronic disease applications. In step two, a framework, which was developed by Kelli Hale and the others, was selected as an appropriate tool. In this framework, the authors have used a behavioral theory content survey (BTS), which is a validated tool for assessing mobile apps according to behavior theory. In the last step, Riezebos's scoring method and the framework were combined as an extension of Riezebos's method. The BTS-based framework was mapped to the Riezebos's method in one of the subsections, which is about the application's content.

Conclusion: The current study introduces an extension of Riezebos's method to assess chronic disease mobile applications. This extension uses a scoring method of Riezebos's peer-review tool with BTS for chronic disease mobile health apps developers.
\end{abstract}

KEYWORDS: Mobile health (mHealth), Mobile application, Assessment method, Chronic disease, Scoring method.

\footnotetext{
Abstracts of First National Congress of Medical Informatics, Mashhad, Iran, February 2017

(C) 2017 The Authors. This is an open access article under the terms of the Creative Commons Attribution-NonCommercialNoDerivs License, which permits use and distribution in any medium, provided the original work is properly cited, the use is non-commercial and no modifications or adaptations are made. 